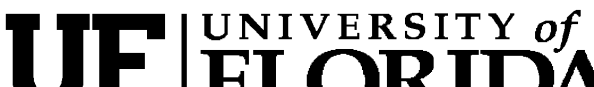 FLORIDA \\ IFAS Extension
}

\section{Hoof Wall Cracks in Cattle 1}

Jan K. Shearer ${ }^{2}$

\section{Introduction}

Cracks or fissures in the hoof wall are common in cattle. Those which run in a vertical direction (from the coronet to the weight-bearing surface) are referred to as vertical wall cracks or sandcracks (See Figure 1). They are particularly common in beef cattle, but less so in dairy cattle. For example, incidence rates as high as $64 \%$ have been reported in beef cattle, compared with less than $1 \%$ in dairy cattle. The percent of cows that may become lame with vertical wall cracks is generally low, but when lameness does occur it may be difficult to treat or manage.

Cracks or fissures that run in a horizontal direction (parallel to the coronet) are referred to as horizontal wall cracks (See Figures 2, 3 and 4). These are common in both beef and dairy cattle and when severe may result in profound lameness. The causes of horizontal wall cracks are better understood. In some cases they simply signal a benign physiological change (usually calving) that has resulted in a mild disruption of hoof horn formation. In others, they are representative of conditions (often related to disease disorders) that have led to significant physiological stress and severe interruption of horn formation in the hoof wall. These severe disruptions in horn formation are exhibited as very distinct ridges and grooves that run in a horizontal direction on the hoof wall. They are often referred to as "hardship grooves" or "stress lines." In the most extreme cases where the fissure is sufficiently deep to result in a full thickness defect of the wall, the lesion is often referred to as a "thimble" (See Figure 4).

\section{Vertical Wall Cracks (Sandcracks)}

Studies indicate that sandcracks occur with a much higher frequency (more than $80 \%$ ) on the outer claws of the front feet as compared with other claws. There are no definitive explanations for this pattern of occurrence, however some have speculated that age (older animals tend to have more sandcracks) and body condition (over-conditioned cows have more sandcracks) may be important predisposing factors. The front limbs carry more than $50 \%$ of the body weight load and front claws tend to have steeper toe angles as compared with rear feet. Also, lesions typically occur near the center of the front wall. Some suggest that the wall is less flexible or resilient in this region and thus more prone to development of

1. This document is VM169, one of a series of the Veterinary Medicine-Large Animal Clinical Sciences Department, Florida Cooperative Extension Service, Institute of Food and Agricultural Sciences, University of Florida. Original publication date August, 2007. Visit the EDIS Web Site at http://edis.ifas.ufl.edu.

2. Jan K. Shearer, D.V.M., MS., IFAS Dairy Extension Veterinarian, Professor, College of Veterinary Medicine - Large Animal Clinical Sciences, Cooperative Extension Service, University of Florida, Gainesville, 32611.

The Institute of Food and Agricultural Sciences (IFAS) is an Equal Opportunity Institution authorized to provide research, educational information and other services only to individuals and institutions that function with non-discrimination with respect to race, creed, color, religion, age, disability, sex, sexual orientation, marital status, national origin, political opinions or affiliations. U.S. Department of Agriculture, Cooperative Extension Service, University of Florida, IFAS, Florida A. \& M. University Cooperative Extension Program, and Boards of County Commissioners Cooperating. Larry Arrington, Dean 
wall cracks. Others speculate that trauma, dehydration, laminitis, or vitamin and/or trace mineral deficiencies may be contributors to the problem in some herds.

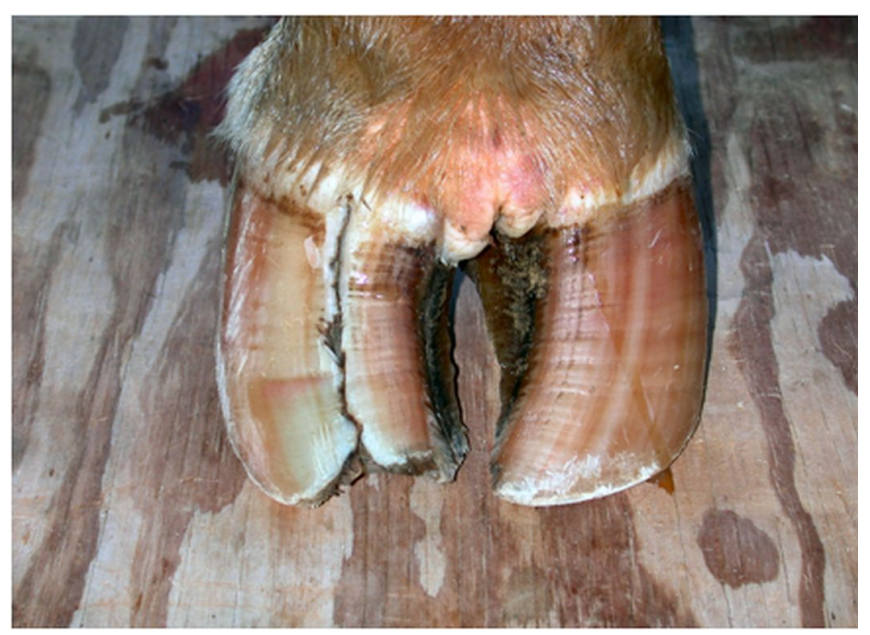

Figure 1. A vertical wall crack or sandcrack in the front or dorsal aspect of the front lateral hoof of a beef cow. This sandcrack extends from the coronet to the weight-bearing surface.

Since vertical wall cracks are a common disorder in beef cows, producers may want to evaluate body condition and consider age as a possible contributing factor. In herds where incidence is high, producers may want to re-evaluate their vitamin and mineral supplementation programs. Biotin, in particular, has attracted much attention in recent years. Although cattle synthesize this vitamin naturally, there is some evidence suggesting that biotin supplementation may be helpful.

Vertical wall cracks are usually benign lesions. However, when they do cause pain resulting in lameness, it is necessary to carefully trim the edges of the lesion (to the depths of the corium if necessary) to remove all foreign debris within the fissure. Pain usually occurs from movement of the wall horn edges that results in pinching of the corium (the sensitive tissue). The application of a foot block is required to relieve pain associated with the vertical crack in a weight-bearing claw and to stabilize the wall horn edges to promote new horn formation and healing. On occasion, lesions and lameness become chronic problems which may require surgical options.

\section{Horizontal Wall Cracks}

The process of calving triggers a number of physiological changes. These changes actually begin prior to calving and progress through calving and the early postpartum period. Animal and dairy scientists and veterinarians have given a great deal of attention to this period in recent years because they have found that proper feeding, housing and management of the cow at this time is key to her performance and health. Dairy cattle producers often refer to it as the "transition period;" that period of time when the cow transitions from a non-lactating to a lactating state. In other words, the cow's body changes its priorities from growing the calf in utero to becoming the sole source of nutrition for the calf during the early phase of its life.

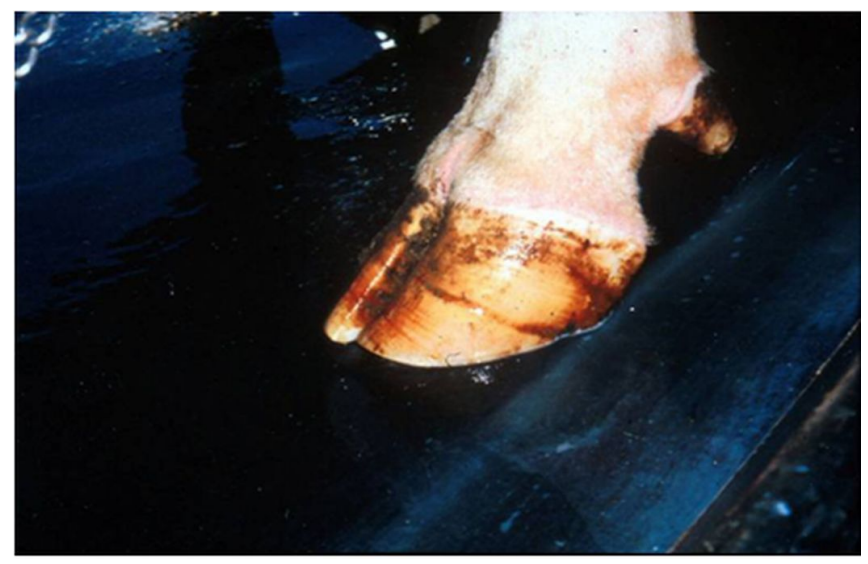

Figure 2. Photo of a horizontal wall crack characteristic of that which may occur as a result of a physiological change associated with calving. Stressful events such as weaning will also cause similar, but on occasion slightly more severe, horizontal wall cracks in calves.

The formation of hoof horn during the transition period becomes a less important physiological priority for the cow. This is reflected in the hoof wall as a visible horizontal line (See Figure 2) or in the cow's horn (See Figure 5) as a ring similar to that found on the cross-section of a tree trunk. The difference is that the ring that forms in the horn is not an indicator of age in years, rather it indicates how many calves a cow has had during the course of her lifetime. For example, a cow that is twelve years old and has had seven calves during her lifetime would have seven rings on her horn, not twelve. 


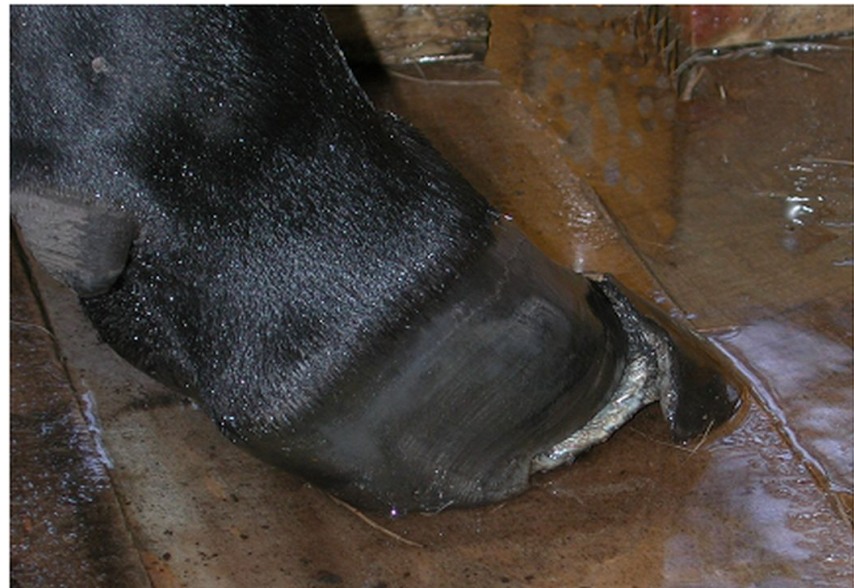

Figure 3. Photo of a horizontal wall crack associated with calving that is suggestive of a more stressful event around the time of calving.

Some people refer to these lines in the hoof wall as stress lines. In most cases they merely represent a period of important physiological change denoting a mild interruption in hoof horn formation. Indeed, evidence suggests that hoof horn tends to wear faster than it grows during the transition period and that this line is not always suggestive of extraordinary stress. On the other hand, stress lines or hardship grooves (See Figures 3 and 4) that are more distinct or deep into the wall are indicative of the compounding of some stressor during this period, such as disease. In such cases, wall horn formation has been severely interrupted or stopped entirely. When horn formation resumes, a full-thickness horizontal wall crack develops which gradually moves downward toward the weight-bearing surface. Frequently, the segment of the wall closest to the weight-bearing surface becomes movable as it nears the weight-bearing surface. When this occurs, it becomes extremely painful as it pinches and damages the underlying sensitive tissues. These lesions look like and are often called "thimbles."

\section{In Summary}

Wall cracks are important disorders in cattle. Vertical wall cracks tend to occur most frequently in beef cattle, but they are relatively rare in dairy cattle. They tend to affect the outer hooves of the front feet and only a small percentage of lesions lead to lameness. Horizontal wall cracks are common to both beef and dairy cattle. They are indicative of physiological change and when severe enough to

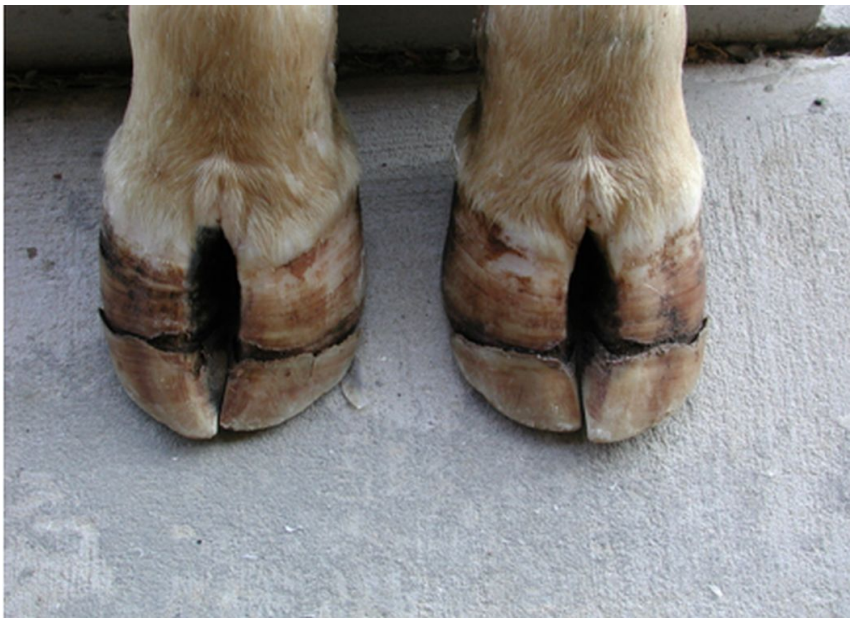

Figure 4. Photo of a "thimble" in the front claws of a cow. These may result in severe lameness as the loose segment reaches the weight bearing surface.

result in a full thickness defect in the wall, suggest complications from disease or some other stressor. Whenever wall cracks result in lameness, corrective trimming procedures and a block fitted to the healthy claw to relieve weight bearing are indicated.

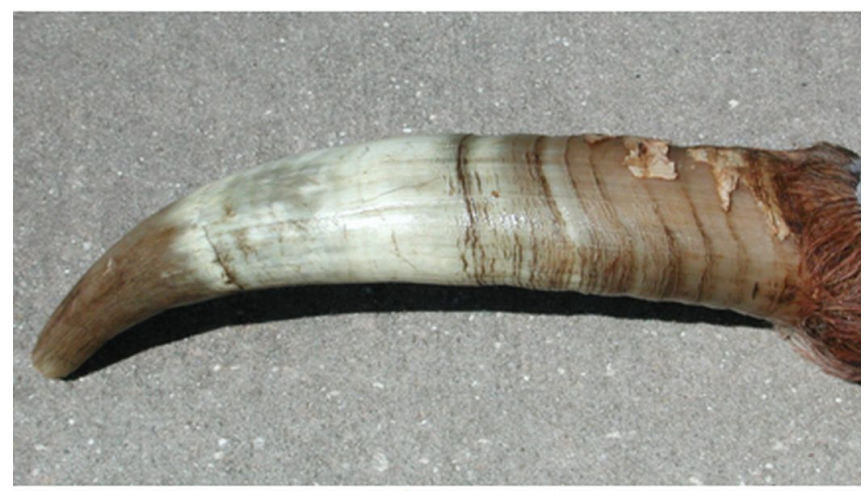

Figure 5. Photo of rings on a horn that indicate the number of calves the cow has had during her lifetime. There are 8 rings indicating that the cow has had 8 calves during her lifetime. 